\title{
Nachruf Altrektor Em.o.Univ.-Prof. Dipl.-Ing. Dr. mont. Peter Paschen
}

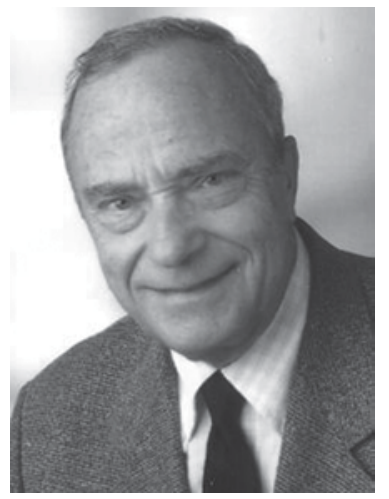

Der ehemalige Rektor der Montanuniversität, Em.o.Univ.Prof. Dipl.-Ing. Dr. mont. Peter Paschen ist am 29. Jänner $2013 \mathrm{im}$ 79. Lebensjahr verstorben.

Peter Paschen wurde am 4. Jänner 1935 in Goslar geboren. Nach dem Abitur 1955 zog es Peter Paschen zum Studium der Metallhüttenkunde nach Leoben und Aachen, hier legte er 1960 das Examen ab. 1965 promovierte Paschen über ein Thema der Bleiraffination und habilitierte sich 1973 an der TU Hannover für das Fach Eisen- und Metallhüttenkunde. Als Privatdozent und Gastprofessor war er an den Technischen Universitäten in Hannover, Delft und Aachen tätig.

Peter Paschen war auch bei seiner Karriere in der Industrie äußerst erfolgreich. Er war von 1960 bis 1984 bei den Firmen Société Métallurgique d'Imphy, Stolberger Zink AG, Preussag AG Metall, Billiton International Metals BV, KHD Humboldt Wedag und KHD do Brasil Ltda. bis hin zur Vorstandfunktion, in Frankreich, Deutschland, Holland und Brasilien tätig. Durch seine intensiven Auslandsaktivitäten und durch seine Begabung sprach Paschen neben Deutsch und Englisch auch Französisch, Holländisch und Portugiesisch.

Im Oktober 1984 erfolgte seine Berufung zum Ordentlichen Professor für NE-Metallurgie an der Montanuniversität Leoben. Diese Funktion füllte er bis zu seiner Emeritierung im Jahr 2003 mit international anerkannter
Fachkompetenz, mit dem für ihn typischen Elan, besonders aber mit seiner menschlichen und die Jugend begeisternden Wesensart aus.

In den Jahren 1995 bis 1999 war Paschen Rektor der Montanuniversität, der erste in hauptamtlicher Funktion im Rahmen der neuen rechtlichen Vorgaben für österreichische Universitäten.

Eine jener Eigenschaften, die Peter Paschen hoch auszeichneten, war sein ehrenamtliches Engagement für die Belange seines Berufsstandes, ein Vorzug, der in unserer Zeit wahrlich nicht selbstverständlich ist. Hervorzuheben sind hier besonders seine Leistungen in der GDMB und beim BVÖ.

Die langjährige Tätigkeit in der GDMB umfasste unter anderem von 1986 bis 1992 die Leitung der Bezirksgruppe Süd der GDMB und die Funktion als Mitglied des Vorstandsrates. Im Jahr 2000 wurde Professor Paschen in das GDMB-Präsidium gewählt, in dem er bis 2004 die Aufgabenbereiche Hochschulen und Internationale Beziehungen übernahm. 2005 wurde Herrn Prof. Paschen die höchste Auszeichnung der GDMB, die Georg-Agricola-Denkmünze, für sein Lebenswerk verliehen. Damit verbunden war gleichzeitig die Ehrenmitgliedschaft in der GDMB.

Als Leiter des Organisationsausschusses für dieTagung " $\mathrm{M}^{3}$ in in Wien 2002 war er Bindeglied und Richtungsgeber für die gemeinsame und sehr erfolgreiche Veranstaltung, die durch die GDMB, den BVÖ und ungarische Fachkollegen getragen wurde.

Peter Paschen hatte durch seinen beispielhaften Einsatz die Entwicklung der Berg- und Hüttenmännischen Monatshefte über viele Jahre maßgeblich beeinflusst.

Neben seiner Tätigkeit als Mitherausgeber war er von 1991 bis 2011, also 20 Jahre, ehrenamtlicher Schriftleiter der BHM. Besonders in dieser Funktion hatte Paschen mit Unterstützung seiner Gattin die inhaltliche, besonders aber sprachliche Qualität der in den BHM erschienenen Beiträge kompromisslos hoch gehalten.

Der Bergmännische Verband Österreichs wird Prof. Paschen stets ein ehrendes Andenken bewahren. 